\title{
Evaluation of reasons for participation refusal among pregnant women in a perinatal outcome research
}

\author{
Vijayan Sharmila $^{1 *}$, Thirunavukkarasu Arun Babu ${ }^{2}$
}

\begin{abstract}
${ }^{1}$ Department of Obstetrics and Gynecology, ${ }^{2}$ Department of Pediatrics, All India Institute of Medical Sciences, (AIIMS), Mangalagiri, Andhra Pradesh, India
\end{abstract}

Received: 09 September 2019

Revised: 04 May 2020

Accepted: 08 May 2020

\section{*Correspondence:}

Dr. Vijayan Sharmila,

E-mail: sharu_jipmer@yahoo.co.in

Copyright: () the author(s), publisher and licensee Medip Academy. This is an open-access article distributed under the terms of the Creative Commons Attribution Non-Commercial License, which permits unrestricted non-commercial use, distribution, and reproduction in any medium, provided the original work is properly cited.

\section{ABSTRACT}

Background: The number of protocol-eligible patients, refusing to participate in a biomedical research is often not mentioned in the results of the studies. There are no studies that have looked at the data on willingness to participate in a research among pregnant women in India. The aim of this study is to report the number of pregnant women who refused to participate and to evaluate the reasons for not participating in a research that was concerned with swabbing of the genital tract for culture.

Methods: A prospective research study was done among healthy pregnant women, that required collection of vaginal swabs for culture to study the vaginal flora. The women eligible to participate in the study were approached for their willingness to participate in the study. The details of women who refused to participate in the study and the various self-reported reasons for their refusal were documented and analysed.

Results: A total $48.2 \%$ of the total protocol-eligible group refused to participate in the study and the refusal rate was alarmingly higher than expected. Some of the common responses for their refusal include reasons such as the study involved tests from their private parts, lack of interest to participate and the need to discuss with their partner or that their partner wound not allow them to participate in research.

Conclusions: It is important for research studies to include data on the refusal to participate and also the reasons why people refuse to participate in research so as to formulate strategies to improve the acceptance rate for participation in research.

Keywords: Participation in research, Participation refusal, Pregnant women, Reasons for refusal, Self-reported reasons

\section{INTRODUCTION}

The progress of medicine depends on biomedical research and human participation is important for conducting research. Ethical conduct in research involving human participants is the principal challenge faced by researchers. A participant's refusal to participate in research is referred to as a non-response in a survey. ${ }^{1}$ In this study, authors have used the term 'refuser' to refer to individuals who declined to take part in research, after being approached by the researcher. Ethical recruitment of participants in a study involves obtaining an informed consent from the participants. ${ }^{2}$ Informed consent for a research requires that participation should be voluntary and securing the anonymity of individuals. ${ }^{3}$ Many studies have investigated the reasons why people participate in biomedical research but, there has been less research on reasons why people refuse to participate in research. ${ }^{4-7}$ There has been no reported studies on evaluation of perspectives of pregnant women who decline to participate in research study in India. In this article, authors explored the reasons why pregnant women 
refused to participate in a research that involved obtaining swabs from their genital tract for culture. Authors also looked into the possible strategies for minimizing refusal rates.

\section{METHODS}

This prospective study was undertaken in the obstetrics and gyn ecology outpatient department at a tertiary care teaching institute in Puducherry, South India. The study was done over a period of 20 months after obtaining the Institute ethics committee clearance.

The study required collection of vaginal swabs from pregnant women to analyze the vaginal flora and later follow up of pregnancy till delivery for obstetric and perinatal outcome. Pregnant women with no history of intake of antibiotics during the two weeks prior to study and no history of preexisting medical disorders complicating pregnancy like diabetes mellitus, hypertension, tuberculosis, heart disease, epilepsy, thyroid dysfunction, jaundice etc., were approached for their willingness to participate in the study. They were counseled about the objectives of the study, the procedure to be done, and the anonymous nature of the study. The participants were free to ask their queries that needed clarification.

The details of pregnant women who accepted and refused to participate in the study were documented. Women who accepted were enrolled for collection of vaginal swabs. The pregnant women who refused to participate in the study were enquired further regarding the reasons for refusal of vaginal swab collection. The various selfreported reasons given by women who refused to participate in the study were documented. The various reasons for participation refusal among pregnant women were explored.

\section{Statistical analysis}

The data was analyzed using SPSS version 20 (SPSS, Chicago, IL, USA).

\section{RESULTS}

About 870 pregnant women were screened for the study, of which 586 women fulfilled the inclusion criteria. A total of 300 out of the 870 protocol- eligible women consented to participate in the study. A total of 286 protocol-eligible women refused to participate in the research study. Response rate for not participating in the study was $48.8 \%$ (Table 1 ).

Distribution of percentages of women who agreed and disagreed to participate in the study according to age, education, socioeconomic status, religion, parity is shown in Figure 1 and Tables 2, 3, 4 and 5 respectively.
Age distribution among women who agreed or refused to participate in the study (Figure 1).

Table 1: Percentages of protocol eligible women who agreed and disagreed to participate in the study.

\begin{tabular}{|ll|}
\hline Protocol eligible women & Percentage \\
\hline $\begin{array}{l}\text { No. of women approached to } \\
\text { participate in the study }\end{array}$ & $586(100 \%)$ \\
\hline Accepted to participate in the study & $300(51.2 \%)$ \\
\hline Refused to participate in the study & $286(48.8 \%)$ \\
\hline
\end{tabular}

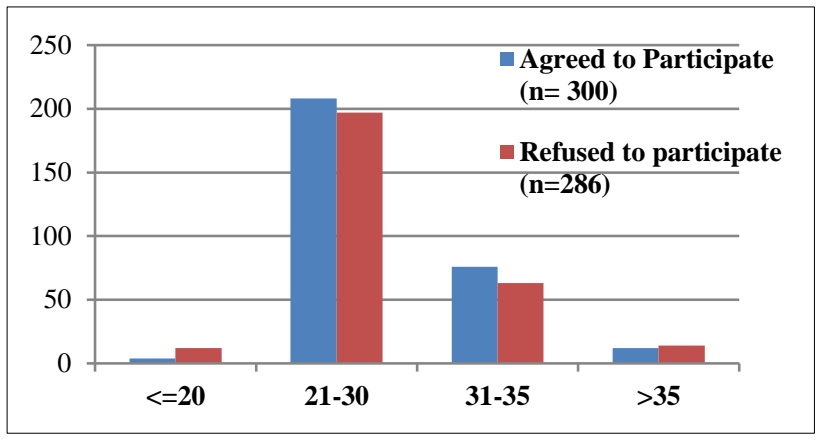

Figure 1: Age distribution among women who agreed or refused to participate in the study.

Table 2: Education status among women who agreed and who refused to participate in the study.

\begin{tabular}{|lll|}
\hline Education & $\begin{array}{l}\text { Agreed to } \\
\text { participate } \\
(\mathbf{n = 3 0 0 )}\end{array}$ & $\begin{array}{l}\text { Refusal to } \\
\text { participate to } \\
\text { participate }(\mathbf{n}=\mathbf{2 8 6})\end{array}$ \\
\hline Illiterate & - & - \\
\hline Primary & $13(4.3 \%)$ & $37(12.9 \%)$ \\
\hline Secondary & $184(61.3 \%)$ & $163(56 \%)$ \\
\hline Tertiary & $103(34.3 \%)$ & $86(30.06 \%)$ \\
\hline
\end{tabular}

Table 3: Parity status among women who agreed or refused to participate in the study.

\begin{tabular}{|lll|}
\hline Gravidity & $\begin{array}{l}\text { Agreed to } \\
\text { participate } \\
(\mathbf{n = 3 0 0 )}\end{array}$ & $\begin{array}{l}\text { Refused to } \\
\text { participate }(\mathbf{n}= \\
\mathbf{2 8 6})\end{array}$ \\
\hline Primi & $195(65 \%)$ & $213(74.5 \%)$ \\
\hline Multi & $105(35 \%)$ & $73(25.5 \%)$ \\
\hline
\end{tabular}

Table 4: Socio economic status among women who agreed or refused to participate in the study.

\begin{tabular}{|lll|}
\hline $\begin{array}{l}\text { Socio economic } \\
\text { class }\end{array}$ & Agreed $(\mathbf{n = 3 0 0 )}$ & $\begin{array}{l}\text { Disagreed } \\
(\mathbf{n = 2 8 6})\end{array}$ \\
\hline I & - & - \\
\hline II & $9(3 \%)$ & $28(9.8 \%)$ \\
\hline III & $34(11.3 \%)$ & $47(16.4 \%)$ \\
\hline IV & $252(84 \%)$ & $193(67.5 \%)$ \\
\hline V & $5(1.7 \%)$ & $18(6.3 \%)$ \\
\hline
\end{tabular}


Majority of women in either group, i.e., who agreed or refused to participate in the study belonged to 20-30 years age group.

Table 5: Distribution of religion among women who agreed or refused to participate in the study.

\begin{tabular}{|lll|}
\hline & Agreed (300) & Disagreed (286) \\
\hline Hindu & $266(88.6 \%)$ & $242(84.6 \%)$ \\
\hline Muslim & $2(0.7 \%)$ & $13(4.5 \%)$ \\
\hline Christian & $29(9.7 \%)$ & $27(9.4 \%)$ \\
\hline Others & $3(1 \%)$ & $4(1.4 \%)$ \\
\hline
\end{tabular}

Authors identified various self-reported reasons why pregnant women had refused to take part in the research study (Table 6).

About $37.4 \%$ of protocol- eligible women refused to participate in the study simply because they were not interested to participate in any research study. About
$62.2 \%$ of people refused and expressed reservations as the study involved swabbing of their private parts.

The results noted that about $52.1 \%$ women responded that they to discuss with their partner prior to consent for participation in a study or felt that they will consider giving consent only after discussing with their partner and $32.5 \%$ of women felt that their partners would not allow them to participate in research. Few participants even commented that they may be scolded by their husbands, if they accept to take part in a study at the hospital. It would have been better if the researchers had approached and explained their partners regarding the nature of the study.

Analysis of the responses also implied that many women had expressed misconceptions and superstitions about the procedure involved in the study such as onset of labor or rupture of membranes $(4.5 \%)$ or vaginal bleeding (4.9\%). About $10.1 \%$ of participants thought that the procedure would be harmful to the fetus.

Table 6: Self-reported reasons for refusal to participate in the study (total count is $>286$ as more than one response was given by 146 women).

\begin{tabular}{|c|c|c|}
\hline Self reported reasons & No. of responders & Percentage \\
\hline As the study involved tests from their private parts & 178 & $62.2 \%$ \\
\hline As they were not interested & 107 & $37.4 \%$ \\
\hline As they feared it would be painful & 24 & $8.4 \%$ \\
\hline As they feared that it would harm the fetus inside & 29 & $10.1 \%$ \\
\hline As they feared that it would cause vaginal bleeding & 14 & $4.9 \%$ \\
\hline As they feared that it would result in labor/ rupture of membranes & 13 & $4.5 \%$ \\
\hline As they need to discuss with their husband & 149 & $52.1 \%$ \\
\hline As they felt that their partner would not like them to participate in a research study & 93 & $32.5 \%$ \\
\hline As they need to discuss with their in-laws & 27 & $9.4 \%$ \\
\hline As they were worried about the test results & 13 & $4.5 \%$ \\
\hline Others & 28 & $9.8 \%$ \\
\hline Did not want to give a response for refusal & 47 & $16.4 \%$ \\
\hline
\end{tabular}

\section{DISCUSSION}

Many studies have evaluated the reasons why people participate in biomedical research..$^{4-7}$ However, there are limited surveys on reasons why people refuse to participate in biomedical research. Most of the data available on refusals is centered on non-response to postal questionnaires from different surveys. ${ }^{8}$

Authors could not find any study that evaluated the refusal rates of pregnant women to participate in longitudinal research studies.

In this study, authors have evaluated the refusal rates among pregnant women and the reasons for their refusal to participate in the research that involved vaginal and rectal swabbing for culture. The results indicate an alarmingly high percentage of refusal (48.8\%).

Several reasons as to why pregnant women refuse to participate in health research have been revealed in this study. Many of these reasons might be applicable to refusal in other similar settings. Knowledge of participants' perspectives and concerns regarding the research may improve the process of informed consent, enhance the trust between participants and researchers and may aid in developing strategies for minimizing refusal rates. ${ }^{9}$

It is important to note that the researcher must always have respect for the decision of the individual for acceptance or refusal to participate in a research. 
With regard to the reasons stated by the pregnant women who did not accept to participate, $37.4 \%$ said that they lacked interest to participate in research. This reflects the need to create strategies to create interest among individuals to participate in research studies

It is also worth emphasizing that $19.5 \%$ reported doubts and concerns regarding the study such as resulting harm to the fetus, onset of labor, leaking or bleeding per vaginum. Women who attend study hospital were mostly from rural and semi-urban areas. Refusal to participate in the research stating these superstitious concerns may be due to ignorance and lack of understanding about the study. Hence, researchers need to know the level of understanding of their potential participants prior to starting the research.

Another important factor identified was the role played by husbands in permitting a woman to participate in research as $52.1 \%$ women felt that they would consider participation after discussing with their husbands and $32.5 \%$ of women felt that their partner would not except for participating in research study. This implies the importance of approaching husbands during the consent seeking process in research studies involving women in developing countries.

According to a study on individuals who refused to participate in biomedical research, the ignorance about the procedure of consent in research, about the objectives of the research and bad previous experiences were related to the reasons for refusal. ${ }^{10}$ According to a study reported in 2016, there was a high prevalence of refusal to participate in research, claiming lack of time for participation, fear of diagnosis disclosure or breach of secrecy and lack of will to participate. ${ }^{11}$

Almeida et al reported in a study, that the expectation of some immediate benefit for oneself and for the community are conditioning factors for consent. ${ }^{10}$ Participation of individuals in clinical studies is important, as the data generated will be useful for the construction of knowledge and improvement of patient care and treatment. ${ }^{12}$ Refusal to participate in a research is likely to affect the timeline of research and also compromise the generalization of the results, since it is unclear as to how people who refused differ from those who agreed to participate in the research.According to the Belmont report participants should be given sufficient information and should be allowed to have enough time for consideration to participate in the research. ${ }^{3}$ They should also be offered an opportunity to ask questions. A number of researchers seem to be in a hurry to implement their studies while neglecting the welfare of their participants which might result in compromising the ethical conduct of research. The results of this study show that obtaining consent for participation in a research, especially a research involving pregnant women is a big challenge.
More scrutiny is needed about participants' perceptions and experiences in health research in order to improve the informed consent process and acceptance rates.

\section{CONCLUSION}

Authors consider that it is important for research studies to include data on the refusal to participate in a study and also the reasons why people accept or refuse to participate in a research. Analysis of these data may contribute to a better understanding of the participants in the research, improving the process of informed consent, and estimating the number of people to be invited for conducting prospective studies. Hence, such data would help researchers to formulate ways of improving the acceptance rates.

Funding: No funding sources Conflict of interest: None declared

Ethical approval: The study was approved by the Institutional Ethics Committee

\section{REFERENCES}

1. McCall N, Khatutsky G, Smith K, Pope GC. Estimation of non-response bias in the Medicare FFS HOS. Health Care Financing Rev. 2004;25(4):27.

2. Lidz CW, Appelbaum PS, Grisso T, Renaud M. Therapeutic misconception and the appreciation of risks in clinical trials. Social Sci Med. 2004;58(9):1689-97.

3. The Belmont report. The National Commission for the Protection of Human Subjects of Biomedical and Behavioral Research. 1979.

4. Brody JL, Waldron HB. Ethical issues in research on the treatment of adolescent substance abuse disorders. J Addict Behav. 2000;25(2):217-28.

5. Smith A, King E, Hindley N, Barnetson L, Barton J, Kim A. The experience of research participation and the value of diagnosis in dementia: implications for practice. J Mental Health. 1998;7:309-21.

6. Farre M, Lamas X, Cami J. Sensation seeking amongst healthy volunteers participating in phase I clinical trials. Br J Clin Pharmacol. 1995;39:405-9.

7. Harrison DA. Volunteer motivation and attendance decisions: competitive theory testing in multiple samples from a homeless shelter. J Appl Psychol. 1995;80:371-85.

8. Ygge BM, Arnetz JE. A study of non-response in a questionnaire survey of parents' views of paediatric care. J Nurs Manag. 2004;12:5-12.

9. Khalil SS, Silverman HJ, Raafat M, El-Kamary S, El-Setouhy M. Attitudes, understanding, and concerns regarding medical research amongst Egyptians: a qualitative pilot study. BMC Med Ethics. 2007;8(9):1472.

10. Almeida CH, Marques RD, Reis DC, Melo JM, Diemert D, Gazzinelli MF. Scientific research in health: an analysis of the participation of vulnerable 
populations. Texto and Contexto-Enfermagem. 2010;19(1):104-11.

11. Guimarães NS, Greco DB, Fausto MA, Kakehasi AM, Guimarães MM, Tupinambás U. Prevalence and reasons for refusal to participate in clinical research. Rev Bioét. (Impr). 2016;24(2):286-91.

12. Mfutso-Bengo J, Masiye F, Molyneux M, Ndebele P, Chilungo A. Why do people refuse to take part in biomedical research studies? Evidence from a resource-poor area. Malawi Med J. 2008;20(2):5763.

Cite this article as: Sharmila V, Babu TA.

Evaluation of reasons for participation refusal among pregnant women in a perinatal outcome research. Int J Reprod Contracept Obstet Gynecol 2020;9:2403-7. 